\title{
High Incidence of Breast Cancer in Light-Polluted Areas with Spatial Effects in Korea
}

\author{
Yun Jeong Kim ${ }^{1,3}$, Man Sik Park², Eunil Lee ${ }^{1,3,4 *}$, Jae Wook Choi ${ }^{1,4,5}$
}

\begin{abstract}
We have reported a high prevalence of breast cancer in light-polluted areas in Korea. However, it is necessary to analyze the spatial effects of light polluted areas on breast cancer because light pollution levels are correlated with region proximity to central urbanized areas in studied cities. In this study, we applied a spatial regression method (an intrinsic conditional autoregressive [iCAR] model) to analyze the relationship between the incidence of breast cancer and artificial light at night (ALAN) levels in 25 regions including central city, urbanized, and rural areas. By Poisson regression analysis, there was a significant correlation between ALAN, alcohol consumption rates, and the incidence of breast cancer. We also found significant spatial effects between ALAN and the incidence of breast cancer, with an increase in the deviance information criterion (DIC) from 374.3 to 348.6 and an increase in $R^{2}$ from 0.574 to 0.667 . Therefore, spatial analysis (an iCAR model) is more appropriate for assessing ALAN effects on breast cancer. To our knowledge, this study is the first to show spatial effects of light pollution on breast cancer, despite the limitations of an ecological study. We suggest that a decrease in ALAN could reduce breast cancer more than expected because of spatial effects.
\end{abstract}

Keywords: Light pollution - breast cancer - spatial analysis - intrinsic conditional autoregressive model

Asian Pac J Cancer Prev, 17 (1), 361-367

\section{Introduction}

Breast cancer is a heterogeneous disease, and its etiology is unclear (Polyak, 2011; Rivenbark et al., 2013). However, recently, circadian disruption has being suggested as a cause of breast cancer (Davis et al., 2001; Althuis et al., 2004; Blask et al., 2005; Haus and Smolensky, 2006; Martinez-Campa et al., 2006; Stevens et al., 2007; Kloog et al., 2008; Srinivasan et al., 2008; Bonde et al., 2012; Jia et al., 2013). Women shift workers were reported to have an increased risk of breast cancer. For example, women aged 50 and older who had experienced more than 3 years of shift work before the age of 30 had a 4.3 times higher risk of breast cancer than non-shift workers (Lie et al., 2006). In addition, a meta-analysis has shown that there is a $40 \%$ increase in the relative risk (RR) of developing breast cancer in women who work at night $(95 \% \mathrm{CI}, \mathrm{RR}=1.19-1.65)$ (Viswanathan and Schernhammer, 2009).

Circadian disruption by exposure to artificial light at night (ALAN) for a long time may be a risk factor for breast cancer in the general population. Geographic information system (GIS) based studies showed a significant correlation between ALAN and breast cancer in Israel, USA, and Korea (Kloog et al., 2008; Bauer et al., 2013; Kim et al., 2015). The communities with the highest ALAN in Israel had a $73 \%$ higher incidence of breast cancer relative to the communities with the darkest environments (Kloog et al., 2008). In the USA study (2000-2007), women who lived in high ALAN intensity exposure regions showed a 1.12-fold increased breast cancer incidence (Bauer et al., 2013). The Korean study also showed a significant association between the prevalence rates for breast cancer and ALAN in urban and rural areas with no association between ALAN and other cancers in women (Kim et al., 2015).

Most of these studies are using a general regression model, without considering the spatial effects, to analyze the association between ALAN and breast cancer. However, it is important to analyze the spatial effects of light polluted areas on breast cancer because light pollution levels are correlated with regions' proximity to light polluted urbanized parts of central cities. Generally, the regions adjacent to each other are not independent and therefore are correlated with each other. If we apply a general regression model without considering spatial effects, the coefficient of regression could be ineffective and the accuracy also could be decreased because of the prediction error created by using a general regression model (Griffith, 1996).

${ }^{1}$ Department of Preventive Medicine, ${ }^{3}$ Molecular, Cellular and Developmental Biology, Division of Biomedical Science, College of Medicine, ${ }^{4}$ Department of Public Health, Graduate School, ${ }^{5}$ Institute for Occupational and Environmental Health, Korea University, ${ }^{2}$ Department of Statistics, College of Natural Sciences, Sungshin Women's University, Seoul, Korea *For correspondence: eunil@ korea.ac.kr 
Spatial patterns of disease incidence and mortality have been reported since historical times, such as in the epidemiology study of cholera by John Snow (1813-1858). Spatial analysis with a statistical model was developed from a map by John Snow showing the clusters of cholera cases in the London epidemic of 1854. He first publicized his theory in an essay "On the Mode of Communication of Cholera" in 1849. He published a second edition with a much more elaborate investigation of the effect of the water supply in the Soho, London epidemic of 1854 by using map clusters.

Cancers also showed spatial patterns or clustering in the USA (Vieira et al., 2005; DeChello and Sheehan, 2007; Shah et al., 2014). Some environmental exposure variables including particulate matter (PM) 10 or asbestos pollution may also show spatial patterns (Juyoung and Dongmug, 2012; Lim et al., 2014). Many studies have suggested that environmental exposures have spatial patterns or clustering; however, few studies have used statistical spatial analysis to assess the spatial effects between exposure and diseases. Therefore, the accuracy of associations between exposure and disease may be increased by analyzing the spatial effects of study variables including spatial dependencies and spatial autocorrelations.

In this study, we used statistical spatial analysis to analyze spatial effects between ALAN and breast cancer incidence in a province of Korea with possible confounding variables including obesity, alcohol consumption rate, and environmental pollution levels such as $\mathrm{O} 3$ and PM10. We identified a significant association between ALAN and breast cancer incidence with spatial effects. To our knowledge, this study is the first study to show spatial effects in an association between ALAN and breast cancer.

\section{Materials and Methods}

\section{Study areas}

The target areas are located in the southwest of South Korea, in Jeollanam-do province and the adjacent Gwangju metropolitan city (Figure 1). The total population of the study area is $3,373,121$ based on the 2010 census (Population Census, 1992-2010). Jeollanam-do province is divided into five cities (Yeosu, Mokpo, Suncheon, Gwangyang, and Naju) and 17 counties. Gwangju city is divided into five districts (Figure 1). We excluded islands, including Sinan and Jindo, because we were considering spatial correlation. Therefore, a total of 25 study areas were analyzed.

\section{Incidence of breast cancer and variables}

Incidence data on breast cancer in the regions were provided by Jeollanam-do Cancer Center (Jeollanamdo Cancer Center, 2008-2010). Information on alcohol consumption and the obesity rate were provided by the Department of Health and Human Services Community Health Survey (Community Health Survey, 2008-2010), and the data on ALAN is from light at night intensity (LAN 6bit, 2008-2010) data collected by U.S. air force weather satellites (DMSP, 2010). The percentage of urbanized areas was provided by the Korea National Housing Corporation's zoning data, and air pollution data (O3, PM10) was from the Ministry of Environment (Korea National Housing Corporation's zoning, 2010; National air pollutants emission, 2010).

\section{Statistical analysis}

We analyzed the distribution of variables on the map using ArcGIS and performed a Poisson regression analysis and a spatial analysis, which is the Poisson regression analysis with spatial effects. The results of the Poisson regression analysis about the correlation between the incidence of breast cancer and light pollution were compared with the results of the spatial analysis. The following hierarchical spatial modeling framework, including the iCAR model, is commonly used in that it can assess the significance of potential factors as well as spatial relationships of areal data:

$$
\begin{aligned}
& \mathrm{Y}\left(\mathrm{s}_{i}\right) \sim \operatorname{Poisson}\left(\lambda\left(\mathrm{s}_{\mathrm{i}}\right)\right) \\
& \log \left(\lambda\left(\mathrm{s}_{i}\right)\right)=\mu\left(\mathrm{s}_{i}\right)+\mathrm{Z}\left(\mathrm{s}_{i}\right), \\
& \mu\left(\mathrm{s}_{i}\right)=\beta_{0}+\beta_{1} \mathrm{X}_{1}\left(\mathrm{~s}_{i}\right)+\beta_{2} \mathrm{X}_{2}\left(\mathrm{~s}_{i}\right)+\ldots+\beta_{\mathrm{p}} \mathrm{X}_{\mathrm{p}}\left(\mathrm{s}_{i}\right), \\
& \mathrm{Z}\left(\mathrm{s}_{i}\right) \sim \operatorname{iCAR}\left(\tau^{2}\right) .
\end{aligned}
$$

Here, $\mathrm{Y}\left(\mathrm{s}_{i}\right)$ stands for the incidence of breast cancer measured at the $\mathrm{i}^{(\text {th })}$ area, $\lambda\left(\mathrm{s}_{i}\right)$ means its expected incidence, $\mu\left(s_{i}\right)$ is a linear combination of explanatory variables such as ALAN, obesity, alcohol consumption rate, and environmental pollution levels, and $\mathrm{Z}\left(\mathrm{s}_{i}\right)$ reflects the spatial association among the areas. A Bayesian statistics package WinBUGS (Version 1.4.3) was used to apply the hierarchical modeling framework to the data. In order to estimate the parameters of our interest, we considered three different sets of initial values and assumed that the prior distributions of the parameters were non-informative. For stabilization of the posterior distributions, we first

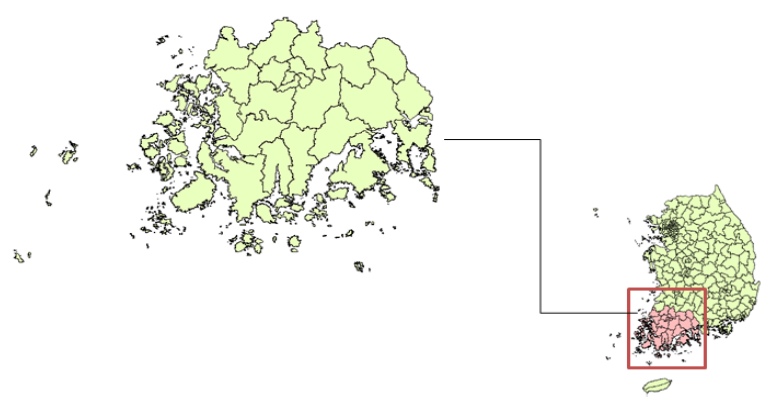

Figure 1. Research Areas

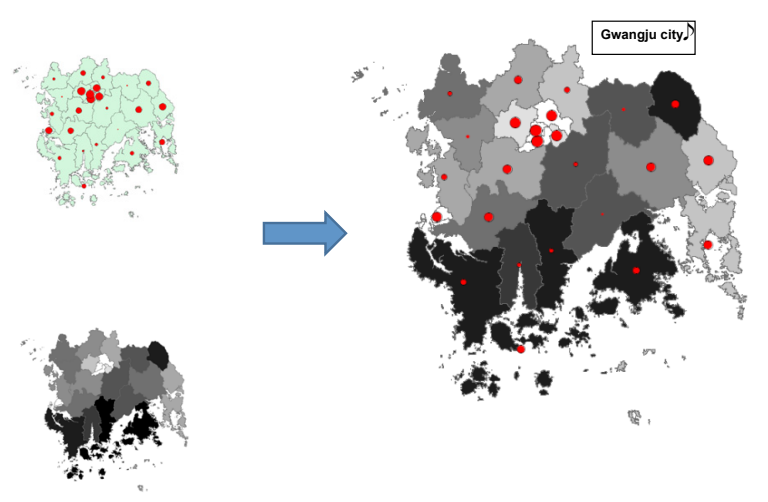

Figure 2. Merged ALAN Intensity and Incidence of Breast Cancer 
removed 50,000 chains from the 100,000 ones per initial set. The deviance information criterion, simply called DIC (Spiegelhalter et al. (2002); Gelman et al. (2004)) was used to find out which model explained the data more accurately: the Poisson regressions with or without spatial effects.

\section{Results}

The distribution of ALAN intensities and incidences of breast cancer in all 27 areas are shown in Figure 2. We showed the incidences of breast cancer and ALAN intensities for each region with a geographic information system (ArcGIS). We overlaid the two figures of breast cancer incidence and ALAN intensities. As can clearly be seen, ALAN intensities and incidences of breast cancer show a very similar pattern, which means the highest light polluted areas have the highest incidences of breast cancer.

Gwangju city showed the highest levels of both breast cancer incidence (31.4) and ALAN (50.5) (Table 1). The ALAN intensity in Gwangju city (50.5) was more than four times higher than the rural areas of Jeollanam-do (10.9), and the incidence of breast cancer in Gwangju city
(31.4) was about two times higher than in the rural areas of Jeollanam-do (18.9). Among other variables, including obesity, alcohol consumption, urbanized parts, $\mathrm{O}_{3}$ and PM10, Gwangju city showed a higher rate of obesity and alcohol consumption than urban and rural areas of Jeollanam-do province.

Poisson regression analysis without considering spatial effects was performed to investigate the effect of risk factors on breast cancer incidence, including ALAN, smoking, alcohol consumption, obesity, O3, PM10, and urbanized parts of each region. A significant association was found between the incidence of breast cancer and ALAN (Table 2). Alcohol consumption rates also showed a significant association with the incidence of breast cancer. The odds ratio of breast cancer by ALAN was 1.383 and by alcohol consumption rate was 1.648.

Furthermore, we performed spatial analysis with an intrinsic conditional autoregressive (iCAR) model to confirm the spatial proximity of the lattice data of ALAN and the incidence of breast cancer. In the iCAR model, both ALAN intensities and alcohol consumption rates showed statistically significant associations with the breast cancer incidence (Table 2). The odds ratio of breast cancer

Table 1. General Characteristics of Gwangju City and Jeollanam-do Province

\begin{tabular}{lrrrrrrrrrr}
\hline Province & $\begin{array}{c}\text { No. } \\
\text { district }\end{array}$ & Population & Breast & ALAN & Smoking & Alcohol & Obesity & $\mathrm{O}_{3}$ & $\mathrm{PM}_{10}$ & Urbanized \\
cancer & & & $(\%)$ & consumption $(\%)$ & $(\%)$ & $(\mathrm{ppm})$ & $\left(\mu \mathrm{g} / \mathrm{m}^{3}\right)$ & parts $(\%)$ \\
\hline Jeollanam-do (urban areas) 5 & $1,047,160$ & 22.4 & 27 & 2.2 & 34.1 & 16.5 & 0.027 & 42 & 16.8 \\
Jeollanam-do (rural areas) & 17 & 871,325 & 18.9 & 10.9 & 1.5 & 24.8 & 17.9 & 0.026 & 42.2 & 12.7 \\
Gwangju city & 5 & $1,454,636$ & 31.4 & 50.5 & 2.5 & 41.1 & 20.3 & 0.023 & 44.8 & 20.8 \\
\hline
\end{tabular}

ALAN: Light intensity at night from DMSP 2010 (nanowatts/cm2/sr); Urbanized parts: The proportion of urbanized parts - the commercial, residential, industrial, or other urban business areas in each district; Breast cancer: Incidence of breast cancer per 100,000 inhabitants

Table 2. Results of Poisson Regression Analysis and Spatial Analysis in Breast Cancer

\begin{tabular}{lcccccccr}
\hline \multirow{2}{*}{ Modeled parameters } & \multicolumn{3}{c}{ Without spatial effect } & \multicolumn{4}{c}{ With spatial effect } \\
\hline ALAN (nanowatts/cm2/sr) & 0.141 & 1.383 & 0.013 & 0.265 & 0.381 & 2.4 & 0.149 & 0.613 \\
Smoking (\%) & -0.007 & 0.993 & -0.16 & 0.022 & -0.161 & 0.852 & -0.315 & 0.786 \\
Alcohol consumption (\%) & 0.217 & 1.648 & 0.01 & 0.45 & 0.482 & 3.03 & 0.912 & 8.722 \\
Obesity (\%) & 0.041 & 1.099 & -0.193 & 0.279 & 0.418 & 2.61 & -3.128 & 4.803 \\
O3 $(\mathrm{ppm})$ & -0.028 & 0.972 & -1.825 & 1.74 & 0.128 & 1.342 & -1.825 & 2.748 \\
PM10 $\left(\mu \mathrm{g} / \mathrm{m}^{3}\right)$ & 0.017 & 1.039 & -0.411 & 0.449 & 0.164 & 1.458 & -7.407 & 7.773 \\
Urbanized parts (\%) & -0.042 & 0.959 & -0.07 & 0.083 & -0.472 & 0.625 & -3.025 & 1.504 \\
DIC & 374.332 & & & & 348.564 & & & \\
$\mathrm{R}^{2}$ & 0.574 & & & & 0.667 & & & \\
\hline
\end{tabular}

DIC: Deviance information criterion, ALAN: Light intensity at night from DMSP 2010 data (unit: nanowatts/cm2/sr); Urbanized parts: The proportion of urbanized parts - the commercial, residential, industrial, or other urban business areas in each district; Bold font represents a credible interval that does not include 0

(A) Observed distributions

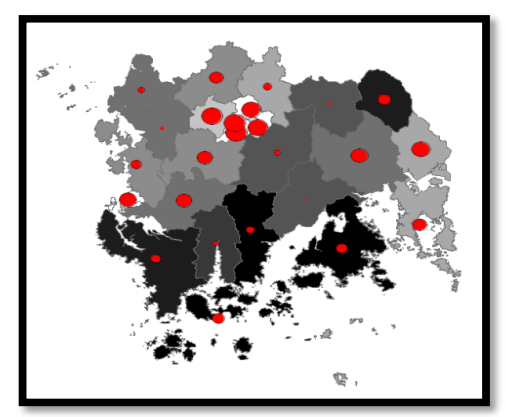

(B) Poisson Model (without spatial effect)

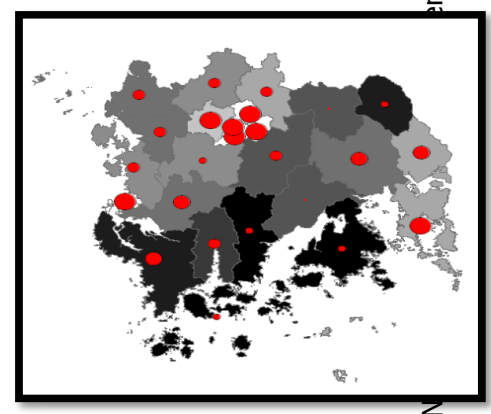

(C) iCAR Model (with spatial effect)s

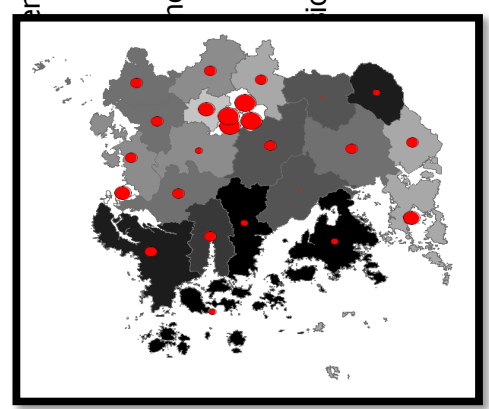

Figure 3. Poisson Model and iCAR Model for Breast Cancer 


\begin{tabular}{|c|c|c|c|c|c|c|c|c|}
\hline \multirow{4}{*}{$\begin{array}{l}\text { Province } \\
\text { Gwangju } \\
\text { city }\end{array}$} & \multirow{3}{*}{$\frac{\text { Areas }}{\text { Gwangsan district }}$} & \multirow{3}{*}{$\begin{array}{c}\text { Observed } \\
\text { BCI }\end{array}$} & \multicolumn{3}{|c|}{ Without spatial effect } & \multicolumn{3}{|c|}{ With spatial effect } \\
\hline & & & \multirow{2}{*}{$\frac{\mathrm{BCI}}{28.6}$} & \multicolumn{2}{|c|}{ 95\% C.I. } & \multirow{2}{*}{$\frac{\mathrm{BCI}}{28.5}$} & \multicolumn{2}{|c|}{ 95\% C.I. } \\
\hline & & & & 24.5 & 32.7 & & 22.5 & 35.4 \\
\hline & Nam district & 31.9 & 33 & 29.5 & 36.6 & 33.6 & 27.9 & 39.9 \\
\hline & Dong district & 31.1 & 32.1 & 28.4 & 35.8 & 33.1 & 26.9 & 40.3 \\
\hline & Buk district & 31 & 31.8 & 28.6 & 34.9 & 31.6 & 26.9 & 36.7 \\
\hline & Seo district & 31.9 & 32.2 & 26.9 & 37.5 & 32.1 & 23.9 & 42.1 \\
\hline Jeolla & Gangjin county & 17 & 21.9 & 18.3 & 25.1 & 21.8 & 18.3 & 25.7 \\
\hline- nam & Goheung county & 23.2 & 20.1 & 16.7 & 24 & 19.8 & 16.6 & 23.4 \\
\hline- do & Gokseong county & 14.1 & 16.9 & 12.5 & 21.4 & 17.7 & 13.2 & 23 \\
\hline \multirow[t]{17}{*}{ province } & Gwangyang city & 30.5 & 24.7 & 21.5 & 30.1 & 23.4 & 20.1 & 27 \\
\hline & Gurye county & 25.2 & 20.4 & 15.9 & 25.2 & 19.9 & 15.2 & 25.4 \\
\hline & Naju city & 27.1 & 21 & 17.6 & 24.7 & 20.3 & 16.5 & 24.6 \\
\hline & Damyang county & 20.8 & 22.5 & 19.5 & 25.5 & 22.2 & 18.8 & 25.9 \\
\hline & Mokpo city & 29.8 & 29.8 & 25.2 & 34.5 & 29.5 & 22.7 & 37.3 \\
\hline & Muan county & 21.4 & 22.3 & 19 & 25.3 & 22 & 18.5 & 26 \\
\hline & Boseong county & 9.9 & 15.2 & 10.4 & 19.7 & 16.3 & 12.1 & 21.2 \\
\hline & Suncheon city & 28 & 24.3 & 20.9 & 27.9 & 23.8 & 19.6 & 28.5 \\
\hline & Yeosu city & 26.7 & 29 & 25 & 32.8 & 29.4 & 23.8 & 35.7 \\
\hline & Yeonggwang county & 18.8 & 22.2 & 18.5 & 25.6 & 22.6 & 18.5 & 27.2 \\
\hline & Yeongam county & 27.1 & 23.1 & 19.6 & 26.8 & 22.7 & 18.6 & 27.5 \\
\hline & Wando county & 24.8 & 20.9 & 16.9 & 25.3 & 20.6 & 16.3 & 25.5 \\
\hline & Jangseong county & 25.4 & 21.9 & 18.8 & 25.2 & 21.9 & 18.2 & 25.9 \\
\hline & Jangheung county & 19.6 & 19.7 & 14.9 & 24.5 & 19.7 & 14.4 & 26.2 \\
\hline & Hampyeong county & 14.2 & 21.9 & 18 & 25 & 22.3 & 18.7 & 26.2 \\
\hline & Haenam county & 21.1 & 23.3 & 19.2 & 27.4 & 23.9 & 19.1 & 29.5 \\
\hline & Hwasun county & 18.6 & 21.5 & 17.4 & 25.5 & 21.8 & 17.1 & 27.1 \\
\hline
\end{tabular}

BCI: breast cancer incidence, $\mathrm{CI}$ : confidence interval
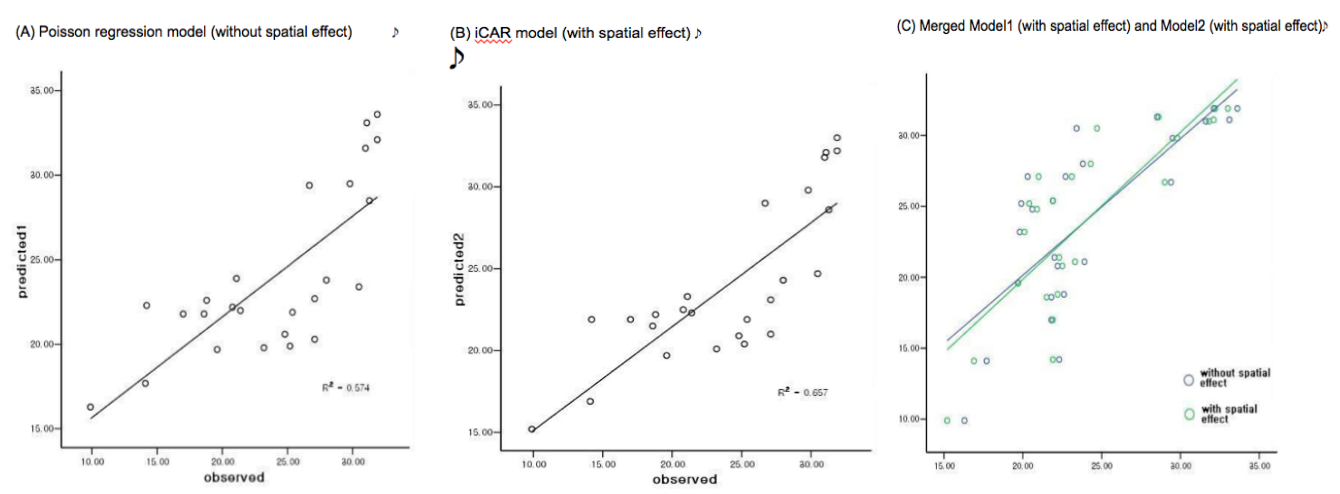

Figure 4. Regression Plot of Observed Values Versus Predicted Values of Breast Cancer. shows the relationship between observed values and predicted values applied to the Poisson regression model (a) and the iCAR model (b). Part c displays the regression plot of observed values versus predicted values of breast cancer incidence. (A) Poisson regression model (without spatial effect); (B) iCAR model (with spatial effect); (C) Merged Model1 (with spatial effect) and Model2 (with spatial effect)

by ALAN was 2.4 and by alcohol consumption rate was 3.03 in the spatial analysis. When we compared the odds ratios from the Poisson regression analysis and the spatial analysis, the odds were higher in the spatial analysis than in the Poisson regression analysis.

These results suggest that an iCAR model to evaluate spatial effects is a more valid analysis than a Poisson regression model. With the spatial effect, the value of the deviance information criterion (DIC) that showed the fitness of the model was decreased (374.332 to $348.564)$, and also $R^{2}$, that is the proportion of the variance explained by the model, was increased ( 0.574 to 0.667$)$. When comparing the distribution of the incidence of breast cancer and ALAN intensities along the observed distribution, the predicted distribution by the Poisson or iCAR models, the predicted distribution by the ICAR model showed greater similarity to the real observed distribution than did the predicted distribution by the Poisson model, especially in the peripheral regions (Figure 3 ). In addition, after calculating the regional average incidence of breast cancer according to the spatial effect with the Winbugs 14 program (Supplementary Table 1), we plotted the regression of observed values and predicted values applied by the Poisson model and the iCAR model (Figure 4). The plot of the iCAR model is closer to observed values.

\section{Discussion}

Disruption of circadian rhythms could cause hormonerelated cancers due to changes in hormones, especially melatonin, one of the pineal gland hormones (Blask et 
al., 2005; Anisimov, 2006). Melatonin levels are related to tumor growth suppression because of cytostatic and cytotoxic activity (Stevens et al., 2007; Cos et al., 2008; Hill et al., 2015). Many studies have addressed the relationship between breast cancer and melatonin levels; in fact, melatonin levels are lower in breast cancer patients than in normal subjects (Viswanathan et al., 2007; Sanchez-Barcelo et al., 2012). Melatonin also has been reported to be a modulator of estrogen-regulated cell proliferation and of the expression of several proteins, such as growth factors and proto-oncogenes (MartinezCampa et al., 2006; Cos et al., 2008). Melatonin downregulates the expression of estrogen receptor (ER)-alpha and inhibits the binding of the estradiol and ER complex to the estrogen response element (ERE) in the DNA (Sanchez-Barcelo et al., 2003).

Reduction of melatonin, which sharply decreases when individuals are exposed to ALAN, could significantly impact cancer prevalence (Schernhammer et al., 2003; Schoenfeld et al., 2003; Davis and Mirick, 2006; Snedeker, 2006; Bhatti et al., 2013). Furthermore, several experimental studies have reported that bright light can enhance tumor growth. In one such study, tumor growth was stimulated by the melatonin depleted blood of women exposed to 2,800 lux bright light in xenografted rats (Blask et al., 2005). Furthermore, exposure to dim lighting during the night time was reported to stimulate tumor progression and increase the rate of tumor growth (Dauchy et al., 1997; Dauchy et al., 1999; Figueiro et al., 2006). Therefore, exposure to light at night for a long time could increase the incidence of breast cancer (Davis et al., 2001; Althuis et al., 2004; Blask et al., 2005; Haus and Smolensky, 2006; Martinez-Campa et al., 2006; Stevens et al., 2007; Kloog et al., 2008; Srinivasan et al., 2008; Bonde et al., 2012; Jia et al., 2013).

Patients who have breast cancer show lower concentrations of urinary 6-sulfatoxymelatonin (6-SMT), the metabolite of melatonin, when compared with normal women (Sanchez-Barcelo et al., 2003; Viswanathan et al., 2007; Schernhammer et al., 2008; Schernhammer and Hankinson, 2009). Furthermore, patients with a longer sleep duration have a high concentration of melatonin and a lower risk of breast cancer (McElroy et al., 2006; Kakizaki et al., 2008; Wu et al., 2008). Also, blind women have a lower risk of breast cancer than sighted women (Coleman and Reiter, 1992; Kliukiene et al., 2001). Even blind women with no perception of light appear to have a lower risk of breast cancer, compared to blind women with light perception (Flynn-Evans et al., 2009).

Recent epidemiological studies show that the more light pollution, the greater the occurrence of breast cancer in the general population. In an Israel study, a populationbased ecological study, there was a $73 \%$ higher breast cancer incidence in the highest ALAN exposed areas in comparison to the lowest ALAN exposed areas (Kloog et al., 2008). The next US study used case-referent analysis of Georgia Comprehensive Cancer Registry data (2000-2007). This US study reported that women who lived in high ALAN exposure regions showed a 1.12-fold increased risk of breast cancer (Bauer et al., 2013). Previously, our study in Korea also showed a high prevalence of breast cancer in light polluted areas in both urban and rural areas (Kim et al., 2015). However, there has been no study to analyze the spatial effects of light polluted areas on breast cancer. A spatial study is necessary because light pollution levels are correlated with regions' proximity to central urbanized areas in studied cities.

We chose Gwangju metropolitan city and Jeollanamdo province because this area is one of the regions that is rapidly becoming severely light polluted in Korea, and the incidence of breast cancer is relatively higher here than in other areas (Jeollanam-do Cancer Center, 2008-2010). We applied an iCAR model to determine whether there was a spatial correlation between ALAN and breast cancer incidence. We found out there was a spatial correlation among the regions. With the spatial effect, the value of DIC was decreased (374.332 to 348.564 ), and $\mathrm{R}^{2}$, that is the proportion of the variance explained by the model, was increased (0.574 to 0.667) (Table 2). Therefore, there are spatial effects between ALAN and breast cancer, and spatial analysis, such as an iCAR model, will be needed to assess ALAN's effects on breast cancer.

Colorectal, lung, and breast cancers showed spatial effects in a Cape-Cod study (Vieira et al., 2005) and a Massachusetts study (DeChello and Sheehan, 2007). Both studies showed that the incidences of the cancers were not explained only by the covariates because the contribution by covariates became more pronounced when spatial effects were considered. These studies showed that a regression model with spatial effects could be a more suitable model to explain the environmental factors and cancer distributions because of the spatial proximity and correlation between disease and environmental factors among regions (Moore and Carpenter, 1999; Vieira et al., 2005; DeChello and Sheehan, 2007; Earnest et al., 2012; Harling and Castro, 2014).

As far as we know, our study may the first to show the spatial effects of ALAN on breast cancer by applying spatial regression analysis. Light pollution is very strong in central urban areas and our results suggest that decreasing ALAN could reduce breast cancer rates more than expected because of the spatial effects of ALAN. We analyzed only Gwangju and Jeollanam-do for our 25 target regions because of the characteristics of spatial analysis for small areas; however, these results may apply to other metropolitan cities and surrounding areas in Korea.

Our ecological study does have limitations. Individual habits such as personal video display terminal use, sleep patterns, and lifestyle were not considered. However, our study could contribute to the knowledge of spatial phenomena of breast cancer associated with ALAN. Therefore, we expect that the results of our study could be used as supportive data to establish anti-light pollution policies, considering regional characteristics with spatial effects.

\section{Acknowledgements}

This work was supported by a future environmental R\&D grant funded by the Korean Environmental Industry and Technology Institute (RE201206020) and the Korea Meteorological Administration Research and 


\section{References}

Althuis MD, Fergenbaum JH, Garcia-Closas M, et al (2004). Etiology of hormone receptor-defined breast cancer: a systematic review of the literature. Cancer Epidemiol Biomarkers Prev, 13, 1558-68.

Anisimov VN (2006). Light pollution, reproductive function and cancer risk. Neuro Endocrinol Lett, 27, 35-52.

Bauer SE, Wagner SE, Burch J, et al (2013). A case-referent study: light at night and breast cancer risk in Georgia. Int $J$ Health Geogr, 12, 23.

Bhatti P, Cushing-Haugen KL, Wicklund KG, et al (2013). Nightshift work and risk of ovarian cancer. Occup Environ Med, 70, 231-7.

Blask DE, Brainard GC, Dauchy RT, et al (2005). Melatonindepleted blood from premenopausal women exposed to light at night stimulates growth of human breast cancer xenografts in nude rats. Cancer Res, $\mathbf{6 5}, 11174-84$.

Bonde JP, Hansen J, Kolstad HA, et al (2012). Work at night and breast cancer--report on evidence-based options for preventive actions. Scand J Work Environ Health, 38, 380-90.

Coleman MP, Reiter RJ (1992). Breast cancer, blindness and melatonin. Eur J Cancer, 28, 501-3.

Cos S, Gonzalez A, Martinez-Campa C, et al (2008). Melatonin as a selective estrogen enzyme modulator. Curr Cancer Drug Targets, 8, 691-702.

Dauchy RT, Blask DE, Sauer LA, et al (1999). Dim light during darkness stimulates tumor progression by enhancing tumor fatty acid uptake and metabolism. Cancer Lett, 144, 131-6.

Dauchy RT, Sauer LA, Blask DE, et al (1997). Light contamination during the dark phase in photoperiodically controlled" animal rooms: effect on tumor growth and metabolism in rats. Lab Anim Sci, 47, 511-8.

Davis S, Mirick DK (2006). Circadian disruption, shift work and the risk of cancer: a summary of the evidence and studies in Seattle. Cancer Causes Control, 17, 539-45.

Davis S, Mirick DK, Stevens RG (2001). Night shift work, light at night, and risk of breast cancer. J Natl Cancer Inst, 93, 1557-62.

DeChello LM, Sheehan TJ (2007). Spatial analysis of colorectal cancer incidence and proportion of late-stage in Massachusetts residents: 1995-1998. Int J Health Geogr, 6, 20.

Earnest A, Hock Ong ME, Shahidah N, et al (2012). Spatial analysis of ambulance response times related to prehospital cardiac arrests in the city-state of Singapore. Prehosp Emerg Care, 16, 256-65.

Figueiro MG, Rea MS, Bullough JD (2006). Does architectural lighting contribute to breast cancer? J Carcinog, 5, 20.

Flynn-Evans EE, Stevens RG, Tabandeh H, et al (2009). Total visual blindness is protective against breast cancer. Cancer Causes Control, 20, 1753-6.

Griffith DA (1996). Spatial autocorrelation and eigenfunctions of the geographic weights matrix accompanying georeferrenced data. Canadian Geographer, 40, 351-67.

Harling G, Castro MC (2014). A spatial analysis of social and economic determinants of tuberculosis in Brazil. Health Place, 25, 56-67.

Haus E, Smolensky M (2006). Biological clocks and shift work: circadian dysregulation and potential long-term effects. Cancer Causes Control, 17, 489-500.

Hill SM, Belancio VP, Dauchy RT, et al (2015). Melatonin: an inhibitor of breast cancer. Endocr Relat Cancer.

Jia Y, Lu Y, Wu K, et al (2013). Does night work increase the risk of breast cancer? A systematic review and meta-analysis of epidemiological studies. Cancer Epidemiol,37, 197-206.

Juyoung K, Dongmug K (2012). Spatial analysis methods for asbestos exposure research. Korean Journal of Environmental Health, 38, 369-79.

Kakizaki M, Kuriyama S, Sone T, et al (2008). Sleep duration and the risk of breast cancer: the Ohsaki Cohort Study. $\mathrm{Br}$ J Cancer, 99, 1502-5.

Kim YJ, Lee E, Lee HS, et al (2015). High prevalence of breast cancer in light polluted areas in urban and rural regions of South Korea: An ecologic study on the treatment prevalence of female cancers based on National Health Insurance data. Chronobiol Int, 32, 657-67.

Kliukiene J, Tynes T, Andersen A (2001). Risk of breast cancer among Norwegian women with visual impairment. $\mathrm{Br} \mathrm{J}$ Cancer, 84, 397-9.

Kloog I, Haim A, Stevens RG, et al (2008). Light at night codistributes with incident breast but not lung cancer in the female population of Israel. Chronobiol Int, 25, 65-81.

Lie JA, Roessink J, Kjaerheim K (2006). Breast cancer and night work among Norwegian nurses. Cancer Causes Control, 17, 39-44.

Lim YR, Bae HJ, Lim YH, et al (2014). Spatial analysis of PM10 and cardiovascular mortality in the Seoul metropolitan area. Environ Health Toxicol, 29, 2014005.

Martinez-Campa C, Alonso-Gonzalez C, Mediavilla MD, et al (2006). Melatonin inhibits both ER alpha activation and breast cancer cell proliferation induced by a metalloestrogen, cadmium. J Pineal Res, 40, 291-6.

McElroy JA, Newcomb PA, Titus-Ernstoff L, et al (2006). Duration of sleep and breast cancer risk in a large populationbased case-control study. J Sleep Res, 15, 241-9.

Moore DA, Carpenter TE (1999). Spatial analytical methods and geographic information systems: use in health research and epidemiology. Epidemiol Rev, 21, 143-61.

Polyak K (2011). Heterogeneity in breast cancer. J Clin Invest, 121, 3786-8.

Rivenbark AG, O'Connor SM, Coleman WB (2013). Molecular and cellular heterogeneity in breast cancer: challenges for personalized medicine. Am J Pathol, 183, 1113-24.

Sanchez-Barcelo EJ, Cos S, Fernandez R, et al (2003). Melatonin and mammary cancer: a short review. Endocr Relat Cancer, 10, 153-9.

Sanchez-Barcelo EJ, Mediavilla MD, Alonso-Gonzalez C, et al (2012). Breast cancer therapy based on melatonin. Recent Pat Endocr Metab Immune Drug Discov, 6, 108-16.

Schernhammer ES, Berrino F, Krogh V, et al (2008). Urinary 6-sulfatoxymelatonin levels and risk of breast cancer in postmenopausal women. J Natl Cancer Inst, 100, 898-905.

Schernhammer ES, Hankinson SE (2009). Urinary melatonin levels and postmenopausal breast cancer risk in the Nurses' Health Study cohort. Cancer Epidemiol Biomarkers Prev, 18, 74-9.

Schernhammer ES, Laden F, Speizer FE, et al (2003). Night-shift work and risk of colorectal cancer in the nurses' health study. J Natl Cancer Inst, 95, 825-8.

Schoenfeld ER, O'Leary ES, Henderson K, et al (2003). Electromagnetic fields and breast cancer on Long Island: a case-control study. Am J Epidemiol, 158, 47-58.

Shah SA, Neoh HM, Rahim SS, et al (2014). Spatial analysis of colorectal cancer cases in Kuala Lumpur. Asian Pac J Cancer Prev, 15, 1149-54.

Snedeker SM (2006). Chemical exposures in the workplace: effect on breast cancer risk among women. Aaohn J, 54, 270-9.

Srinivasan V, Spence DW, Pandi-Perumal SR, et al (2008). Melatonin, environmental light, and breast cancer. Breast 
Cancer Res Treat, 108, 339-50.

Stevens RG, Blask DE, Brainard GC, et al (2007). Meeting report: the role of environmental lighting and circadian disruption in cancer and other diseases. Environ Health Perspect, 115, 1357-62.

Vieira V, Webster T, Weinberg J, et al (2005). Spatial analysis of lung, colorectal, and breast cancer on Cape Cod: an application of generalized additive models to case-control data. Environ Health, 4, 11.

Viswanathan AN, Hankinson SE, Schernhammer ES (2007). Night shift work and the risk of endometrial cancer. Cancer Res, 67, 10618-22.

Viswanathan AN, Schernhammer ES (2009). Circulating melatonin and the risk of breast and endometrial cancer in women. Cancer Lett, 281, 1-7.

Wu AH, Wang R, Koh WP, et al (2008). Sleep duration, melatonin and breast cancer among Chinese women in Singapore. Carcinogenesis, 29, 1244-8. 